\title{
HUMANIZEM PRIMOŽA TRUBARJA
}

\author{
Ključne besede: humanizem, renesansa, reformacija, protestantizem, \\ Primož Trubar
}

Govoriti o humanizmu Primoža Trubarja (okrog 1508-1586) $\mathrm{z}$ vidika tradicionalnega zgodovinopisja pomeni govoriti predvsem o tistih prvinah v njegovem življenju in delu, ki jih lahko opredelimo kot renesančno-humanistične. Izraz humanizem kot oznaka za specifično »kulturno in umetnostno gibanje v renesansi « je sicer skovanka $\mathrm{z}$ začetka 19. stoletja in je $\mathrm{v}$ renesančnih spisih samih ne najdemo. Se pa v njih pojavljata izraza »studia humanitatis« in »humanista«, pri čemer se pojem humanistični študij(i) nanaša na gramatiko, retoriko, poetiko, zgodovino in moralno filozofijo, humanist pa je učitelj, ki te predmete poučuje in/ali se jim kako drugače posveča. $\mathrm{V}$ dobi renesanse s koreninami v letih okrog 1300 in z zgornjo časovno mejo konec 16. ali v prvih desetletjih 17. stoletja ${ }^{2}$ »humanizem « poleg tega ni bil niti samostojen učni predmet niti ni veljal za filozofsko smer ali vedo. Izrazito vzgojnemu in književno-jezikovnemu gibanju renesančnih humanistov je širše razsežnosti začel pridajati razsvetljenski pól

1 V jubilejnem Trubarjevem letu 2008 je bilo Trubarju posvečenih več simpozijev in bolj ali manj znanstvenih razprav. Veliko novih poudarkov in spoznanj, tudi temeljnih biografskih, prinaša knjiga Vera in hotenja. Študije o Primožu Trubarju in njegovem času, ur. S. Jerše, Ljubljana, 2009). Po zadnjih ugotovitvah se je Trubar rodil med letoma 1507 in 1509, (Golec, 2009, 46-47). Renesančni humanizem pri Trubarju so do zdaj (delno) obravnavali Barbarič, Š., Ideje humanizma v delih slovenskih protestantov, v: Slavistična revija 24 (1976), 409420; Simoniti, P., Humanizem na Slovenskem in slovenski humanisti do srede XVI. stoletja, Ljubljana, 1979; Simoniti, P., Med humanisti in starimi knjigami, Ljubljana, 2007; Ahačič, K., Zgodovina misli o jeziku in književnosti na Slovenskem. Protestantizem, Ljubljana, 2007.

2 Prim. Nauert (2006, 8, 200); Burke (2004, 25-26). 
18. stoletja, ki je v njem videl zaveznika v boju zoper onstranske, proč od človeka usmerjene cilje in vrednote srednjega veka (Nauert, 2006, 8). S temi pridržki je uporaba têrmina humanizem vendarle na mestu. Kot pomemben segment renesančne kulture je namreč humanizem prek raznovrstnih antičnih zgledov dejansko pripomogel $\mathrm{k}$ »čedalje tanjšemu posluhu za [človekovo] individualnost na osebnem področju in tudi v življenju posebnih, zlasti narodnostnih skupnosti«.

Kljub reformaciji in protestantizmu, ki sta neizbrisno zaznamovala Trubarjevo ožje in širše okolje ter njega samega, humanistična načela v tistem času niso izgubila pomena. Prav nasprotno: njihov prodor v šole in na univerze se je verskim razprtijam navkljub skoraj povsod nadaljeval. Leta 1524, ko si je Trubar bržčas že širil humanistično znanje v Trstu (Rupel, 1962a, 22 sl.), sta se dokončno razšla Erazem Rotterdamski in Martin Luther. Toda razid takrat najuglednejšega humanista in tisti čas vodilnega reformatorja ni zmanjšal prepričanja, da je za opravljanje velikega dela javnih služb nujna humanistična izobrazba. Tega prepričanja ni omajal niti sklep Tridentinskega koncila (1545-1563), naj ostane v veljavi Vulgata, čeravno je bil s tem zadan hud udarec humanističnemu vodilu »nazaj $\mathrm{k}$ virom«. Ob nadaljnjem razvoju protestantizma in katolicizma so se porodile celo nove oblike humanizma. Peter Burke ugotavlja, da izvira »nekaj najbolj dognanih in uspelih zgledov za tekmo z Italijo in antiko v likovni umetnosti, glasbi in književnosti prav iz tega časa, ne od prej« (Burke, 2004, 137). V drugi polovici 16. stoletja povrh tega prvič naletimo na izraz humanist v modernih jezikih: v španščini leta 1552, v francoščini 1554 in v angleščini leta 1589 (Burke, 2004, 163).

Pri obravnavi humanističnih prvin v Trubarjevem življenju in delu si spričo dejstva, da je humanizem opredeljiv kot pojav oziroma gibanje, pa tudi kot medij (Walther, 2002, 436), lahko pomagamo s tremi vprašanji: kje se je Trubar srečeval s humanizmom in humanisti, ali in kje najdemo pričevanja o njegovih humanističnih pogledih in kolikšen je oziroma bi utegnil biti njegov vpliv na širjenje humanistične misli. Po zdajšnjem védenju se je Trubar s humanizmom prvič srečal v Trstu, kjer je tamkajšnji škof Peter Bonomo klerikom na svojem dvoru v italijanščini, nemščini in slovenščini razlagal Vergilija in Erazma Rotterdamskega (Trubar, 1989, 95). Kot je v svoji izčrpni monografiji o Bonomu pokazal Stefano di Brazzano, se je 
Trubar s škofovim tolmačenjem Vergilija in Erazma, natančneje Erazmovih Paraphrases Novi testamenti, seznanil v času svojega prvega bivanja $\mathrm{v}$ Trstu sredi dvajsetih let 16. stoletja (Di Brazzano, 2005, 327). Prav z verzom iz Vergilijeve Eneide, $\mathrm{z}$ "gesto, vredno Bonomove humanistične šole«, je Trubar leta pozneje počastil spomin svojega učitelja in zaščitnika. »Et bene apud memores veteris stat gratia facti« (Aeneis IV, 539) je zapisal v marginalijo posvetila $\mathrm{k}$ Ta prvemu dejlu tiga Noviga testamenta, objavljenem $\mathrm{v}$ Tübingenu leta $1557 .{ }^{3}$

Diplomatu in humanistu Petru Bonomu (1458-1546) je Trubar slej ko prej dolgoval tudi (utrditev) vezi s švicarskim humanistično zaznamovanim reformacijskim gibanjem. Te vezi naj bi se spletle od novembra 1540 do aprila 1541, ko je Trubar zadnjič bival v Trstu (Di Brazzano, 2005, 324, 329). Jasne potrditve za to resda nimamo: 13. marca 1557 Trubar v pismu Heinrichu Bullingerju (1504-1575), nasledniku Ulricha Zwinglija, izrazi hvaležnost Bonomu, a ne neposredno v tej zvezi. Trubar je ponosen, ker ga je v Trstu "vzgajal od nežne mladosti škof Peter Bonomo, poet in zelo pobožen mož« (Trubar, 1986, 29), vendar se njegove besede pojavljajo v kontekstu italijanske reformacije in znanja italijanskega jezika. ${ }^{4}$ Iz leto in pol starejšega Trubarjevega pisma Bullingerju je po drugi strani mogoče sklepati, da je Trubar Bullingerjeva dela (ter dela Konrada Pellicana) poznal že pred prihodom v Trst jeseni 1540 (Trubar, 1986, 23-24). To sicer ne izključuje Bonomovega posredništva, saj je Trubar s škofom lahko ves čas ohranjal stike. Pri tem ne gre spregledati, da je bilo vsaj po letu 1540 Bonomovo teološko razumevanje, zlasti razumevanje evharistije, blizu teologiji švicarskih reformatorjev. ${ }^{5} \mathrm{~V}$ pismu Bullingerju iz leta 1557 navaja Trubar še eno ugledno ime švicarskega »humanističnega protestantizma« pokojnega župana St. Gallna Joachima von Watta Vadiana (1484-1551). Bonomo in Vadian pa sta imeni, tesno povezani z nekaj desetletij zgodnejšim razcvetom dunajskega humanizma pod cesarjem Maksimilijanom I. (1486/1508-1519). ${ }^{6}$ Kljub temu, da ta predreformacijski humanizem ni

3 Prim. Trubar $(1989,95)$; Barbarič $(1976,412)$.

4 Prim. Di Brazzano (2005, 324 sl.)

5 Prim. Di Brazzano (2005, 329, op. 188; 355); Dolinar (2000, 100).

6 Prim. Simoniti (1979, 227-228); Di Brazzano (2005, 161-162). 
mogel neposredno vplivati na Trubarja, ki je na Dunaj odšel študirat leta 1528 (Rupel, 1962b, 424), je mogoče v njegovih spisih sem ter tja opaziti nekonfesionalno humanistično ozaveščenost. Izraz takšne ozaveščenosti je denimo Trubarjevo opravičilo Bullingerju, da nerad piše v latinščini, ker se boji, da ne bi pri tem »napravil sintaktične napake in grešil zoper Prisciana« (Trubar, 1986, 29). Koliko je bil Trubar v resnici vešč latinskega jezika, težko ocenimo; v očeh ljubljanskega škofa Tomaža Hrena (umrl 1630), odličnega latinista, ${ }^{7}$ je bil véliki reformator »le nekoliko humanistično izobražen « (Trubar, 2009, 27, 34), kar pa je treba spričo Hrenove protireformacijske drže jemati s pridržkom.

V splošnem pri Trubarju prevladuje dediščina t. i. krščanskega humanizma, porojenega v prvih desetletjih 16. stoletja »v misli in črki« Francoza Jacquesa Lefèvra d'Etaplesa (okrog 1460-1536) in predvsem Holandca Erazma iz Rotterdama (okrog 1467-1536). Temeljni cilj krščanskega humanizma, ki je črpal navdih iz krščanske in poganske antike, je bil prenova Cerkve in vere, za nepogrešljivo sredstvo za dosego tega cilja pa so veljala »studia humanitatis «. ${ }^{8}$ Trubarja s krščanskim humanizmom povezuje zlasti vodilo »ad fontes«, nanašajoče se tako na Sveto pismo kakor na Cerkev kot ustanovo in skupnost vernikov, kar izpričujejo Trubarjeve kritike na račun nenravnosti in praznoverja v katoliški Cerkvi. Erazma Trubar v svojih spisih večkrat omenja, pri čemer te omembe pričajo, da je Trubar poznal posamezna Erazmova dela, med njimi izdaji cerkvenih očetov Hieronima in Janeza Krizostoma (Barbarič, 1976, 413). Analiza Trubarjevega prevoda Matejevega evangelija iz leta 1555, ki jo je opravil Kozma Ahačič, po drugi strani kaže, da se je Trubar pri prevajanju naslonil na Erazmov latinski prevod Nove zaveze iz leta 1542 (Ahačič, 2007, 273). Poleg tega je še vedno premalo znan podatek, da je bil Trubar prvi, ki je v slovenščini uporabil izraz »retorika«, več odmevnih del s tega področja pa je napisal prav Erazem (Ahačič, 2007, 283, 285-287). Po Trubarjevi določbi v Cerkovni ordningi (1564) naj bi pred posebno komisijo kandidati za protestantske pridigarje v latinščini dokazovali, ali pravilno razumejo »Grammatico, Dialectico, Rhetorico«; po Ahačiču gre obenem za »edino pojavitev te besede v slovenščini

\footnotetext{
7 Prim. Gantar $(1989,89$ sl.)

8 Prim. Tüchle (1994, 13 sl.); Theologen $(2002,11)$.
} 
v 16. stoletju « (Ahačič, 2007, 290). Zanimivo je, da se Trubar v svojem opusu na Erazma sklicuje - kot je že pred leti opozoril Štefan Barbarič - samo do leta 1562, ko postane Trubarjeva najvišja avtoriteta Luther (Barbarič, 1976, 415).

V okviru obravnavane problematike zasluži posebno pozornost Trubarjeva samooznaka »rodoljub ilirski«, Philopatridus Illiricus, v naslovu prve slovenske knjige - Katekizma iz leta 1550 (Trubar, 1970, 1). Oba člena, »Philopatridus« in »Illiricus«, sta namreč del obzorja, skupnega nacionalno oziroma etnično čutečim humanistom. Rodoljubje, $s$ katerim se ponaša Trubar, je jasen izraz humanistične zavesti o posebnosti lastnega jezika in etnosa, vpetima v širši okvir vseslovanske skupnosti (Simoniti, 2007, 155 sl.). »Odkritje« humanistov je tudi izraz »ilirski«; za Eneja Silvija Piccolominija so Iliri Slovani na ozemlju antičnega Ilirika (Simoniti, 2007, 161), za Trubarjevega sodobnika, švicarskega humanista Konrada Gessnerja, pa je ilirski jezik med vsemi jeziki najbolj razširjen slovanski jezik. ${ }^{9}$ In kar je v našem primeru še povednejše: za Trubarjevega rojaka Pavla Obersteina so Iliri očitno Slovenci, slovensko govoreči prebivalci Štajerske, Koroške in Kranjske pa za Petra Freyländerja, denimo, »ilirski narodi«, katerih »sijaj « je ljubljanski škof Krištof Ravbar (Simoniti, 2007, 165-166). Škof Ravbar (umrl 1536) pa je tisti škof, pod katerim je začel Trubar sredi tridesetih let 16. stoletja službovati kot stolni pridigar $\mathrm{v}$ Ljubljani in nekaj let pozneje kot ljubljanski kanonik ostriti svoje reformacijsko-teološke poglede. ${ }^{10}$

Veliko prelomnico v Trubarjevem življenju brez dvoma pomeni leto 1547, ko je na ljubljanskem sodnem procesu proti krivoverstva osumljenim duhovnikom izgubil vse kanoniške in druge cerkvene dohodke. ${ }^{11} \mathrm{~V}$ povezavi s procesom se namreč postavlja vprašanje, ali in v kolikšni meri so bile ideje (krščanskega) humanizma navzoče med ljubljansko duhovščino v obdobju, ko je pri stolni cerkvi oziroma v kapitlju deloval Trubar. Med takratnimi humanistično izobraženimi in »novi veri« naklonjenimi ljubljanskimi kanoniki izstopa Pavel Wiener (okrog 1495-1554), poznejši prvi evangeličanski škof v Hermannstadtu (Sibiu) na Sedmograškem. Ba-

9 Prim. Ahačič $(2007,232)$; Rotar $(1988,330)$.

10 Prim. Kidrič (1978, 92 sl.); Žnidaršič Golec $(2000,289)$.

11 Prim. Trubar (1986, 65); Žnidaršič Golec (2000, 144 sl.). 
kalavreat iz svobodnih umetnosti, ki ga je Wiener leta 1517 pridobil na Dunaju, sam po sebi ne izpričuje Wienerjeve privrženosti tedaj konfesionalno še neobremenjenemu humanizmu. Toda dejstvo, da je Wiener na dunajski univerzi, na katero se je vpisal leta 1514, študiral v obdobju, ko je kot poeta laureatus ter profesor retorike in rektor tam deloval že imenovani Joachim Vadian, ${ }^{12}$ temu prej pritrjuje kot nasprotuje. Pri Vadianu na Dunaju se je že kot otrok učil Sebastijan Kolbeck, od okrog leta 1520 imetnik enega od beneficijev pri ljubljanski stolnici in v letih 1526-1557 izpričani prošt kolegiatnega kapitlja v Novem mestu. Wienerju in Kolbecku pa ni skupen le vpis v Turnirsko knjigo Gašperja Lambergerja; zdi se, da ju je družila zlasti naklonjenost protestantizmu. ${ }^{13}$

Glede na povedano je torej zelo verjetno, da je Trubarjeva humanističnoprotestantska misel v Ljubljani zorela ob Wienerju, morda Kolbecku ter še kakšnem, danes manj znanem stolnem duhovniku. Po drugi strani je Trubar v glavno mesto dežele Kranjske prej ko ne zanesel ta ali oni idejni poudarek iz Bonomovega tržaškega kroga. Po procesu, ki ga je vodil ljubljanski škof Urban Textor (umrl 1558), sam humanist, in umiku na tuje konec leta 1547 ali v začetku 1548 se je Trubar še nekajkrat vrnil v Ljubljano. Najdlje, približno tri leta, je v obdobju 1562-1565 zasedal mesto superintendenta, tj. škofa kranjske luteranske Cerkve (Rupel, 1962a, 142-181). Vendar pa takrat pri stolni cerkvi in v kapitlju ni bilo več oseb, ki bi (krščanski) humanizem odkrito združevale s protestantizmom. Znamenja humanizma je sicer mogoče zaslediti tudi v navzven pokatoličanjenem kapiteljskem okolju: leta 1556 so ljubljanskim škofijskim duhovnikom na primer predstavili govor De dignitate sacerdotii oratio, ki »dignitas" kot značilno humanističen topos obrača na duhovništvo. Njegov avtor, dunajski jezuit Sulenij Columna, je besedilo posvetil ljubljanskemu kanoniku Mihaelu Frankoviču. ${ }^{14}$

Antična pisca, pesnik Vergilij in gramatik Priscian, véliki krščanski humanist Erazem Rotterdamski, humanisti in reformatorji Peter Bonomo, Jo-

12 Prim. Žnidaršič Golec (2000, 295); Simoniti $(1979,178)$.

13 Prim. Bonorand (1980, 97); Žnidaršič Golec (2000, 257-258, 295-296); Arbenz (1908, $533-$ 535).

14 Predstavitev in objava govora Simoniti (2008, 373-404). 
achim Vadian in Heinrich Bullinger in v Ljubljani Pavel Wiener ter škofa Krištof Ravbar in Urban Textor so osebe, ki jih srečujemo, ko sledimo Trubarjevemu humanizmu. Humanist po v njegovem času že splošno sprejetih izobrazbenih idealih se je Trubar kot duhovnik, najprej katoliški in po letu 1547 nedvoumno protestantski, navdihoval predvsem pri krščanskem humanizmu. Toda bolj kot humanizem ga je zanimalo krščanstvo. To se med drugim zrcali v dejstvu, da je Sveto pismo prevajal po latinskih in drugih prevodih in ne po predlogah v izvirnih, tj. $\mathrm{v}$ hebrejskem in grškem jeziku. Laže in primerneje kakor o Trubarjevem širjenju humanističnih pogledov je zato govoriti o Trubarjevem širjenju protestantskega krščanstva, pri katerem sta očeta slovenskega knjižnega jezika vodila »občutek poklicanosti k oznanjevanju prave krščanske vere in želja oblikovati pristno krščansko skupnost med prelubimi Slovenci« (Jerše, 2009, 27). Nič manj opazna ni pri Trubarju »humanitas" - »humanitas« kot človekoljubje in na svoj način »humanitas « v pomenu "plemenitost duha «, ki je vsebovan tudi v naslovu te revije. Vendar pa Trubarjeva človekoljubje in plemenitost duha nista več tema na (renesančni) humanizem omejenega prikaza.

\section{VIRI}

Primož Trubar, Catechismus in der Windischen Sprach, Ljubljana, 1970 (faksimile).

Primož Trubar, Deutsche Vorreden zum slowenischen und croatischen Reformationswerk, izd. O. Sakrausky, Wien, 1989.

Primož Trubar, Pisma, prev. in izd. J. Rajhman, Ljubljana, 1986.

\section{LITERATURA}

Ahačič, K., Zgodovina misli o jeziku in književnosti na Slovenskem. Protestantizem, Ljubljana, 2007. 
Arbenz, E. (ur.), Die Vadianische Briefsammlung der Stadtbibliothek St. Gallen VI (1541-1551), v: Mittheilungen zur vaterländischen Geschichte 30 (1908).

Barbarič, Š., Ideje humanizma v delih slovenskih protestantov, v: Slavistična revija 24 (1976), 409-420.

Bonorand, C., Joachim Vadian und der Humanismus im Bereich des Erzbistums Salzburg, St. Gallen, 1980.

Di Brazzano, S., Pietro Bonomo (1458-1546), diplomatico, umanista e vescovo di Trieste. La vita e l'opera letteraria, Trieste, 2005.

Burke, P., Evropska renesansa. Središča in obrobja, Ljubljana, 2004.

Dolinar, F. M., L'influsso di Pier Paolo Vergerio sul Protestantesimo sloveno, v: Pier Paolo Vergerio il Giovane, un polemista attraverso l'Europa del Cinquecento, ur. U. Rozzo, Udine, 2000, 97-105.

Gantar, K., Hrenova mladostna pesniška zbirka: latinska verzifikacija med humanizmom in barokom, v: Obdobje baroka $v$ slovenskem jeziku, književnosti in kulturi, Ljubljana, 1989, 89-98.

Golec, B., Kdo in od kod je bil pravzaprav Primož Trubar? Trubarjev novi »rojstni list« in popravljena »osebna izkaznica«, v: Vera in hotenja. Študije o Primožu Trubarju in njegovem času, ur. S. Jerše, Ljubljana, 2009, 45-64.

Jerše, S., Vera in hotenja. Silhuete religioznosti v zgodnjem novem veku, v: Vera in hotenja. Študije o Primožu Trubarju in njegovem času, ur. S. Jerše, Ljubljana, 2009, 13-29.

Kidrič, F., Ogrodje za biografijo Primoža Trubarja (1923), v: Izbrani spisi I, Ljubljana, 1978, 57-113.

Nauert, C. G., Humanism and the Culture of Renaissance Europe, New York, $2006^{2}$.

Novak, F., Trubarjev Philopatridus Illyricus, v: Jezikoslovni zapiski. Merkujev zbornik 13 (2007), 1-2, 297-302.

Rotar, J., Viri Trubarjevega poimenovanja dežel in ljudstev in njegova dediščina, v: Zgodovinski časopis 42 (1988), 3, 315-361.

Rupel, M. (a), Primož Trubar. Življenje in delo, Ljubljana, 1962.

Rupel, M. (b), Primus Truber an der Wiener Universität, v: Die Welt der Slaven 7 (1962), 423-427. 
Simoniti, P., Humanizem na Slovenskem in slovenski humanisti do srede XVI. stoletja, Ljubljana, 1979 (nem. prevod: Humanismus bei den Slovenen. Slovenische Humanisten bis zur Mitte des 16. Jahrhunderts, ur. M. Wakounig, prev. J. Wakounig, Wien, 2008).

Simoniti, P., Med humanisti in starimi knjigami, Ljubljana, 2007.

Simoniti, P., O dostojanstvu duhovništva - govor jezuita Sulenija Columne na sinodi škofijske duhovščine v Ljubljani leta 1556. Liturgia Theologia Prima. Zbornik ob osemdesetletnici profesorja Marijana Smolika. CeljeLjubljana 2008, 373-404.

Theologen des 16. Jahrhunderts. Humanismus - Reformation - Katholische Erneuerung, izd. M. H. Jung, P. Walter, Darmstadt, 2002.

Trubar, Hren, Valvasor, Dolničar. O slovstvu na Kranjskem, ur. L. Vidmar, Ljubljana, 2009.

Walther, G., Nation als Exportgut. Mögliche Antworten auf die Frage: Was heisst Diffusion des Humanismus?, v: Diffusion des Humanismus. Studien zur nationalen Geschichtsschreibung europäischer Humanisten, ur. J. Helmrath, U. Muhlack, G. Walther, Göttingen, 2002.

Zgodovina Cerkve. Reformacija in protireformacija 3 (1500-1715), ur. H. Tüchle, C. A. Bouman, J. Le Braun, Ljubljana, 1994.

Žnidaršič Golec, Lilijana, Duhovniki kranjskega dela ljubljanske škofije do tridentinskega koncila, Ljubljana, 2000. 


\title{
THE HUMANISM OF PRIMOŽ TRUBAR
}

Keywords: Humanism, Renaissance, Reformation, Protestantism, Primož Trubar

\begin{abstract}
In order to determine the role of (Renaissance) humanism in the life and work of the "father of standard Slovenian" Primož Trubar (ca. 1508-1586), this study raises the following questions: 1) Where did or could Trubar encounter humanist ideas and meet their propagators? 2) Are there elements in his thought and writings that can be associated with humanism? 3) Did he help spread humanist values and, if so, to what extent? Trubar first encountered humanism around age sixteen at the court of the bishop of Trieste, Peter Bonomo (1458-1546), one of the leading Viennese humanists under Emperor Maximilian I (d. 1519). The young Trubar belonged to a group of clerics that attended the bishop's readings of Virgil and Desiderius Erasmus of Rotterdam. It was through Bonomo that Trubar must have come into contact with the Swiss humanist and Protestant reformer Heinrich Bullinger (1504-1575). Trubar's writings, especially his letters and Bible translations, reveal the prevailing influence of Christian humanism. Criticizing clerical abuses and popular superstitions, Trubar presents himself as an advocate of Church reform and renewal. On the other hand, he often refers directly to Erasmus, "the crowning glory of the Christian humanists." Moreover, Kozma Ahačičs systematic analysis of Ta evangeli svetiga Matevža (The Gospel of Matthew, 1555) shows that Trubar's translation was based on the Basel edition of Erasmus's Novum Testamentum (1542). Apart from the written word, Trubar highly appreciated preaching; his sermons, aimed at promoting "the true Word of God," could likewise transmit (Christian) humanist ideals. However, the historical sources provide insufficient information to enable a reliable assessment of Trubar's contribution to the spread of humanism.
\end{abstract}

